\title{
Sistemas de Informação e Tecnologia da Informação integrados com Planejamentos Municipais: Estudo de Caso em 14 Pequenas Cidades do Rio Grande do Sul, Brasil
}

\author{
Information systems and information \\ technology integrated to municipal \\ planning: case study in 14 small cities of \\ Rio Grande do Sul, Brazil
}

\author{
Denis Alcides-Rezende* \\ José Augusto-Guagliardi \\ ANDRÉA ZAMIN-SAAD
}

\begin{abstract}
The objective of this work is to analyse the integration of information systems and information technology resources in the municipal planning of 14 small cities of Rio Grande do Sul (Brazil). The research methodology consisted of a multiple case study together with a convenient non-probabilistic sample chosen through a research protocol. The results demonstrate the difficulties of these cities to organise the municipal data as well as their struggle for accessibility of information and planning for management and control.
\end{abstract}

Keywords: information systems, information technology, municipal planning, strategic integration and aligning, city manegement.

\section{Resumo}

O objetivo deste trabalho é analisar a integração dos sistemas de informação e dos recursos da tecnologia da informação nos planos e nos planejamentos municipais de 14 pequenas cidades do Rio Grande do Sul (Brasil). A metodologia da pesquisa enfatizou um estudo de caso múltiplo com uma amostra não probabilística por conveniência, por meio de um protocolo de pesquisa. Os resultados demonstram as dificuldades das cidades na organização dos dados municipais, na disponibilização de informações e nos planejamentos para fins de controles e gestão.

Palavras-chave: sistemas de informação, tecnologia da informação. planejamentos municipais, integração e alinhamento estratégico, gestão de cidades.

*Universidade de São Paulo. Correio-e: denis.rezende@pucpr.br, jaguar@usp.br, andreasaad@fw.uri.br. 


\section{Introdução}

As cidades (ou municípios) estão competindo entre si por razões políticas, e econômicas e também para oferecer uma qualidade de vida diferenciada aos seus cidadãos. Essa competitividade exige diferenciadas formas de gerir a cidade e demandam competências inexoráveis dos gestores municipais nas suas ações cotidianas, que envolvem os cidadãos e os diversos atores relacionados com a cidade. As prefeituras brasileiras obedecem a novas legislações e enfrentam um ambiente competitivo, globalizante e turbulento, necessitando realizar sua reestruturação, reorganização, flexibilização, adaptação e modificação de forma política, social, ambiental, financeira e econômica, para continuarem atuantes de forma competente e participativa. Os instrumentos da administração e da tecnologia da informação são fundamentais para os gestores das cidades nas suas ações cotidianas e estratégicas. Nesse contexto, o relevante papel da tecnologia da informação (incluindo os sistemas de informação) deve ser revisto e principalmente deve estar integrado ou alinhado com as atividades das prefeituras e das cidades.

São requeridos exaustivos exercícios práticos embasados em profunda fundamentação teórica para integrar e alinhar os emergentes recursos da tecnologia da informação aos serviços municipais. Esses exercícios estão relacionados às atividades cotidianas, dinâmicas e inteligentes dos planos e planejamentos municipais, dos sistemas de informação, da tecnologia da informação e respectivas gestões. Tais atividades devem ser elaboradas de forma integrada e estruturadas, onde as informações oportunas e os conhecimentos personalizados são fatores essenciais para a gestão competente e participativa. Não acontece da noite para o dia a estruturação dos dados da cidade e a disponibilização compartilhada das informações e dos conhecimentos dos cidadãos. Essas atividades exigem das prefeituras planejamento e gestão a curto, médio e longo prazo. A partir dessa estruturação e disponibilização, os sistemas de informação, a tecnologia da informação e seus recursos podem agregar valores aos serviços municipais, contribuindo com a gestão e com o desenvolvimento das mesmas. Inúmeras são as atividades auxiliadoras que os sistemas de informação, a tecnologia da informação podem realizar nas cidades para desempenhar seus papéis operacionais e estratégicos, podendo ser empregados como fundamentais ferramentas para auxiliar na realização de seus objetivos, 
atuando por intermédio de seus gestores de forma ativa, planejada, participativa e oportuna.

As aplicações da tecnologia da informação também podem ajudar na junção de forças reconciliadoras da estabilidade das mudanças fiscais, sociais, ambientais, legais e financeiras. Podem contribuir focando esforços nas ações competentes das atuações cotidianas, adaptando-se às mudanças freqüentes, mantendo-se atualizada, melhorando seu desempenho, gerando resultados sociais profícuos, antecipando informações, gerando cenários, avaliando tendências, satisfazendo os cidadãos e adequando seus serviços à comunidade local e aos demais interessados (atores sociais ou stakeholders).

As 5563 cidades brasileiras apresentam inúmeros problemas em diversos indicadores urbanos, rurais, ambientais, habitacionais, sociais, culturais, fiscais, financeiros, econômicos, legais e também estratégicos (IBGE, 2007; Cidades, 2004). Muitos poderiam ser minimizados ou resolvidos por meio da elaboração e controle dos planos e planejamentos municipais e da gestão competente destas. Para que os serviços municipais possam ser de qualidade, produtivos, efetivos, dinâmicos, modernos, perenes, competitivos, inteligentes e participativos, os planos e planejamentos municipais devem ser elaborados de forma competente e integrados com a comunidade local e demais interessados. Nesse sentido a tecnologia da informação pode contribuir com a organização de dados, sistematização de informações e disseminação de conhecimentos, quando está integrada ou alinhada com os planos e planejamentos municipais.

Lamentavelmente de maneira trivial e tradicional, muitos métodos de planos e planejamentos municipais usam os recursos da tecnologia da informação como processos elementares nas cidades, focando seus esforços apenas em recursos tecnológicos, principalmente por falta de visão sistêmica e estratégica do uso desses recursos tecnológicos integrados ou alinhados aos serviços municipais. Inclusive, todos os gastos com tecnologia da informação, nas prefeituras, devem ser justificados e participados para os cidadãos, a fim de evitar o desperdício de dinheiro, as despesas inúteis em tecnologia e principalmente danos municipais irrecuperáveis.

Todas essas dificuldades relatadas, em especial, acontecem com mais ênfase nas pequenas cidades, tendo em vista seus limitados recursos disponíveis. 
As cidades que possuem dados atualizados, informações oportunas e conhecimentos personalizados, formalmente organizados e dinamicamente planejados, têm a prerrogativa de tomar decisões com qualidade, agir com produtividade, efetividade e transparência.

O objetivo desse trabalho é analisar a integração dos sistemas de informação e dos recursos da tecnologia da informação nos planos e nos planejamentos municipais de 14 pequenas cidades do Rio Grande do Sul (Brasil). Para atingir esse objetivo, a tecnologia da informação será entendida como uma ferramenta tecnológica de gestão municipal (contemplando inclusive os sistemas de informação), sem ênfase nos recursos de software e hardware.

\section{Fundamentação teórica}

Determinados conceitos devem ser fundamentados, discutidos, entendidos e disseminados. A fundamentação deve levar em conta a inexorável Lei de Responsabilidade Fiscal, a Constituição Federal, o Estatuto da Cidade e a Lei Orgânica Municipal. O Estatuto da Cidade abrange um conjunto de princípios que expressam cidade, planos e planejamentos municipais integrados (Estatuto da cidade, 2005).

As cidades preocupadas com sua gestão, com as questões sócio-ambientais e com a qualidade de vida dos seus cidadãos devem integrar ou alinhar os seus diferentes planos e planejamentos municipais, que podem compreender os seguintes instrumentos integrados: plano plurianual municipal; plano diretor municipal; planejamento estratégico municipal; políticas municipais (incluindo programa de governo); projetos participativos municipais; planejamento de recursos humanos; e planejamento de informações e tecnologias.

\subsection{Gestão pública, gestão urbana e gestão municipal}

O conceito de gestão, sob a ótica da administração, está relacionado com o conjunto de recursos decisórios e a aplicação das atividades destinadas aos atos de gerir (Mintzberg et al., 2000). A gestão pública está direcionada com a capacidade dos governos na gestão das funções federais, estaduais e municipais, bem como, com a competência na implementação de respectivas políticas públicas para facilitar as ações necessárias na condução 
do país, dos estados e das cidades, contextualizando a participação dos cidadãos nesses desafios (Frey, 2000; Ferrari, 1986).

A gestão urbana pode ser entendida como a gestão da cidade. Está relacionada com o conjunto de recursos e instrumentos da administração aplicados na cidade como um todo, visando à qualidade da infra-estrutura e dos serviços urbanos, propiciando as melhores condições de vida e aproximando os cidadãos nas decisões e ações da governança pública municipal. Já a gestão municipal, como a gestão da prefeitura e de seus órgãos, institutos, autarquias e secretarias está relacionada com o conjunto de recursos e instrumentos da administração aplicada por meio de seus servidores públicos municipais (Rezende e Castor, 2006).

Gestão pública, gestão urbana e gestão municipal requerem discussões sobre administração pública, onde o Estado e seus modelos de gestão têm um papel relevante. As funções do Estado estão relacionadas com a alocação de recursos oriundos da arrecadação tributária, a distribuição dos recursos com eqüidade e justiça e finalmente, a estabilização econômica, social, política e institucional (Marini, 2003). Tais desafios requerem conceitos de gestão e planejamento estratégico, triangulando projeto de governo, governabilidade e governança (Matus, 1993).

\subsection{Planos municipais}

O Plano Diretor da cidade também é chamado de Plano Diretor Municipal ou Planejamento Urbano. As cidades brasileiras passam e passarão por mudanças profundas que poderão garantir um futuro de desenvolvimento equilibrado. Também poderão universalizar o direito à moradia digna em ambiente saudável para todos os seus cidadãos. Para tanto, as cidades têm de contar com fontes estáveis e seguras de financiamento para o desenvolvimento urbano indispensável para que estas possam manter e expandirem-se adequada e democraticamente. Entretanto, para que isso seja possível, os cidadãos também terão que enfrentar um grande desafio nos próximos anos, o de instituir formas de planejamento e controle do território municipal. Juntos, a gestão urbana e a gestão municipal e os cidadãos podem utilizar os potenciais e limites do seu meio físico, as potencialidades abertas pela existência de redes de transporte e logística em seus territórios. De forma que os impactos de seu crescimento e desenvolvimento não se traduzam em desequilíbrios e deseconomias, como tem sido as experiências recentes de urbanização. Planejar 
o futuro da cidade, incorporando todos os setores sociais, econômicos e políticos que a compõe, de forma a construir um compromisso entre cidadãos e governos na direção de um projeto que inclua todos, é o desafio que o Estatuto da Cidade impõe a todos os planos diretores (Ferrari, 1986; Cidades, 2004). Os princípios que norteiam o Plano Diretor estão contidos no Estatuto da Cidade onde esse plano está definido como instrumento básico para orientar a política de desenvolvimento e de ordenamento da expansão urbana do município (Estatuto da cidade, 2002). É obrigatório para municípios: com mais de 20 mil habitantes; integrantes de regiões metropolitanas e aglomerações urbanas; com áreas de especial interesse turístico; situados em áreas de influência de empreendimentos ou atividades com significativo impacto ambiental na região ou no país (Cidades, 2004).

O Plano Plurianual é exigido pela Constituição Federal (Artigo 165) que estabelece o sistema orçamentário federal regulado por três leis: a Lei do Plano Plurianual (PPA); a Lei de Diretrizes Orçamentária (LDO); e a Lei Orçamentária Anual (LOA). O PPA é de periodicidade quadrienal, avançando um ano no próximo governo. É um instrumento do planejamento municipal que estabelece os objetivos, as estratégias e as ações da administração pública municipal para as despesas de capital e outras delas decorrentes, bem como para as relativas aos programas de duração continuada. Dele se derivam a LDO e LOA. O Plano Plurianual Municipal (PPAM) é uma peça de planejamento do município e da prefeitura de médio prazo para conduzir efetivamente o orçamento e os gastos públicos municipais durante a sua vigência, para manter o patrimônio público e também para elaborar investimentos coerentes com as receitas e despesas municipais. A LDO é de periodicidade anual. Estabelece um conjunto de instruções em termos de normas de forma e o conteúdo com que a lei orçamentária de cada exercício deve ser apresentada para indicar as prioridades a serem observadas em sua elaboração. A LOA é de periodicidade anual e proverá os recursos necessários para cada ação constante da LDO (Cidades, 2005; Vainer et al., 2005). O PPAM norteia e orienta o governo municipal quanto à realização dos programas de trabalho para o período citado, ressaltando todas as obras que se pretenda realizar no período, assim como também os programas de natureza continuada, como, por exemplo, aqueles relacionados com educação e saúde. Dessa forma, qualquer ação governamental municipal somente poderá ser executada durante o ano (execução orça- 
mentária) se o programa estiver adequadamente inserido no PPAM (Andrade et al., 2005).

\subsection{Planejamentos municipais}

O Planejamento Estratégico Municipal (PEM) é um processo dinâmico e interativo para determinação dos objetivos, estratégias e ações do município e da prefeitura. É elaborado por meio de diferentes e complementares técnicas administrativas com o total envolvimento dos atores sociais, ou seja, cidadãos, gestores das cidades e demais interessados na cidade. É formalizado para articular políticas federais, estaduais e municipais visando produzir resultados no município e gerar qualidade de vida adequada aos seus cidadãos. É um projeto urbano global que considera os aspectos sociais, econômicos e territoriais. É uma forma participativa e contínua de pensar o município no presente e no futuro (Rezende e Castor, 2006). Segundo Pfeiffer (2000) o PEM é um instrumento de gerenciamento que, como qualquer outro, tem um único propósito: tornar o trabalho de uma cidade ou prefeitura mais eficiente. O enfoque estratégico no desenvolvimento local diminui as indecisões e favorece as transformações econômicas, sociais e políticas nas cidades, para tratar com coerência a multiplicidade de iniciativas sobre o município, buscando um consenso entre os múltiplos atores (inclusive o governo) na seleção de um futuro desejável e factível (Llona et al., 2003). Para Lopes (1998) o PEM coordena os vários níveis e funções estratégicas de uma cidade em um projeto global, considerando a missão, as estratégias, o orçamento e o controle dos objetivos e das ações municipais. Ainda, Motta (2004) reitera que o planejamento é uma forma de aprendizado sobre as demandas e necessidades externas e sobre a capacidade de resposta da administração pública municipal para revelar expectativas e referências de valor, essências a um grupo de trabalho.

Todo projeto deve ser elaborado com uma metodologia adequada, viável, dinâmica e inteligente. Como o PEM é um projeto do município, ele requer uma metodologia coletiva para sua elaboração e implementação. Para Matus (1987) a metodologia deve atender a um planejamento estratégico situacional. De forma análoga e embasada em diversos autores precursores, Rezende e Castor (2006) recomendam uma metodologia com fases elaboradas, com equipes multidisciplinares e com a participação efetiva do cidadão: análises estratégicas; diretrizes estratégicas; es- 
tratégias e ações municipais; e controles municipais e gestão do planejamento.

O Planejamento de Recursos Humanos está relacionado com a discussão, definição e capacitação das pessoas requeridas para a elaboração e implementação dos planos e planejamentos municipais. Deve ser definido o perfil profissional necessário pala a elaboração dos planos e planejamentos municipais (incluindo os cidadãos). Num segundo momento deverá ser definido o perfil das pessoas para a implementação dos planos e planejamentos municipais (Rezende y Castor, 2006).

O Planejamento das Informações e das Tecnologias está relacionado com a discussão, definição e organização das informações e das tecnologias necessárias para a elaboração e implementação dos planos e planejamentos municipais. Essas tecnologias são de todos os tipos, tais como, industriais, comerciais, de serviços e também a tecnologia da informação (Boar, 1993; Turban et al., 1996; Lederer e Mahaney, 1996; Rezende, 2004).

\subsection{Sistemas de informação e tecnologia da informação}

Um sistema de informação propõe como saída, o resultado do processamento de dados ou de recursos a serem transformados, por exemplo, informação, seja por recursos computacionais ou não (Stair, 1996; O’Brien, 2001). Os sistemas de informação poderão contribuir significativamente para a solução de muitos problemas municipais, à medida que os mesmos gerem informações efetivamente oportunas e personalizadas. Os sistemas de informação têm como maior objetivo o auxílio dos processos decisórios da prefeitura. O seu foco deve estar direcionado para os serviços municipais. Devem ser considerados como ferramentas para determinar fatores diferenciais da prefeitura (Rezende, 2004).

Um efetivo sistema de informação pode ter resolutividade operacional, um grande impacto nas estratégias municipais e no sucesso das prefeituras, beneficiando as mesmas, os cidadãos e qualquer indivíduo ou grupo que interagir com os sistemas municipais (Stair, 1996). Os benefícios dos SI são amplamente relatados e justificados na literatura e nos artigos pertinentes. Eles devem se apresentar como instrumentos geradores de fatores de solução dos problemas municipais (Freitas et al., 1997; Laudon e Laudon, 1996). Para facilitar as soluções de problemas municipais, os sistemas de informação devem estar integrados e com 
relação de interdependência entre os subsistemas envolvidos, que resultam principalmente na troca de informações entre eles. Essa integração também pode ser chamada de visão sistêmica, abordagem sistêmica, visão de floresta, engrenagem municipal, sinergia da informação ou conjunto harmônico das funções organizacionais. Desta forma, os sistemas de informação podem se apresentar como subsistemas de informação ou funções organizacionais, divididos em: produção ou serviços; comercial ou marketing; materiais ou logística; financeiro; jurídico legal; recursos humanos e seus respectivos módulos (Rezende, 2004). Somente com a integração desses subsistemas será possível produzir informações oportunas e personalizadas.

Os níveis das informações e das decisões nas prefeituras podem obedecer à hierarquia padrão existente na maioria das organizações (pirâmide organizacional). Estes níveis são conhecidos como estratégico, tático e operacional. O tipo de decisão que é tomada em cada nível requer diferente grau de agregação de dados e de informação. Os diferentes níveis de decisões requerem diferentes informações nos seus diversos tipos de produtos externados, tais como telas, relatórios, etc. $\mathrm{Na}$ prática não existe uma classificação rígida, permitindo aos interessados e às prefeituras, classificarem seus sistemas de diversas maneiras. Genericamente os sistemas de informação podem ser classificados em operacional, gerencial e estratégico (Kroenke, 1992; Kendall e Kendall, 1992; Bio, 1993; Stair, 1996; Freitas et al., 1997; Laudon e Laudon, 1996). A principal diferença entre os sistemas de informação nessa classificação está na forma de apresentação das informações para seus usuários. Os Sistemas de Informação Operacionais fornecem informações no seu detalhe. Os Sistemas de Informação Gerenciais disponibilizam informações agrupadas ou sintetizadas. E os Sistemas de Informação Estratégicos possibilitam as comparações das informações tanto no meio ambiente interno da prefeitura e externo entre outros municípios, inclusive gerando indicadores e alguns conhecimentos.

Outro modo de classificar os sistemas de informação é segundo a abrangência das prefeituras. Desta forma, existem os sistemas nos níveis: pessoal; de grupo (ou departamental); organizacional; e interorganizacionais, nos quais se enquadram os sistemas globais de informação, envolvendo várias prefeituras de diferentes cidades (Kroenke, 1992).

A tecnologia da informação pode ser conceituada como recursos tecnológicos e computacionais para guarda de dados, ge- 
ração e uso da informação. Está fundamentada nos seguintes componentes: hardware e seus dispositivos e periféricos; software e seus recursos; sistemas de telecomunicações; gestão de dados e informações (Stair, 1996; Turban et al., 1996).

Os sistemas de telecomunicações e seus respectivos recursos são subsistemas especiais do sistema de informação global das organizações. As comunicações podem ser definidas como as transmissões de sinais por um meio qualquer, de um emissor para um receptor. As telecomunicações se referem à transmissão eletrônica de sinais para comunicações. As comunicações de dados são um subconjunto especializado de telecomunicações que se referem à coleta, processamento e distribuição eletrônica de dados, normalmente entre os dispositivos de hardware de computadores.

A gestão de dados e informações compreende as atividades de guarda e recuperação de dados, níveis e controle de acesso das informações (Norton, 1996). Requerendo para essa gestão um completo plano de contingência e um plano de segurança de dados e informações. Todos estes componentes interagem e necessitam do componente fundamental que é o recurso humano (Boar, 1993).

Quanto às tecnologias da informação aplicadas à geração de informações oportunas e conhecimentos organizacionais personalizados, podem ser destacadas: executive information systems; enterprise resource planning; sistemas de apoio a decisões; sistemas gerenciadores de banco de dados; data warehouse; inteligência artificial; sistemas especialistas; data mining; database marketing; recursos da internet e portais; automação de escritórios; recursos on-line analytic processing e on-line transaction processing; gerenciamento eletrônico de documentos; groupware; workflow e automação de processos; software de business intelligence; ferramentas de apoio à inovação e produtos; software específico; entre diversas outras (Stair, 1996; Laudon e Laudon, 1996; O’Brien, 2001).

O Planejamento Estratégico da Tecnologia da Informação (PETI) é um processo dinâmico e interativo para estruturar estratégica, tática e operacionalmente as informações organizacionais, os sistemas de informação, a tecnologia da informação (e seus recursos: hardware, software, sistemas de telecomunicações, gestão de dados e informações), as pessoas envolvidas e a infra-estrutura necessária para o atendimento de todas as decisões, ações e respectivos processos da organização (Premkumar e King, 1992; Boar, 1993; Turban et al., 1996; Lederer e Mahaney, 1996; Stair, 1996; Rezende, 2004). 
O alinhamento entre o PETI e os planos e planejamentos municipais pode se constituir a partir das satisfatórias relações verticais, horizontais, transversais, dinâmicas e sinérgicas das funções municipais e os recursos da tecnologia da informação. A integração ou o alinhamento pode promover o ajuste ou a adequação operacional e estratégica das tecnologias disponíveis de todo Município, como uma ferramenta de gestão municipal contemplada pelos conceitos de qualidade, produtividade, efetividade, modernidade, perenidade, rentabilidade, inteligência competitiva e inteligência municipal (Rockart e Morton, 1984; Henderson e Venkatraman, 1993; Boar, 1993; Rezende, 2004).

\section{Metodologia da pesquisa}

A metodologia de pesquisa empregada se constitui numa abordagem de natureza aplicada numa realidade circunstancial, favorecendo o método indutivo das experiências vivenciadas dos autores pesquisadores, tanto em projetos de assessoramento e pesquisa-ação em cidades como em projetos acadêmicos em sala de aula de graduação e mestrado (Nachmias e Nachmias, 1987; Gil, 1999). Foi aplicada porque gerou novos conhecimentos úteis para o avanço da ciência e para verificação prática dirigidos à solução ou facilitação de problemas relativos às variáveis do estudo de caso múltiplo (Marconi e Lakatos, 1996).

Os procedimentos metodológicos foram divididos em duas fases. Na primeira fase teve ênfase na abordagem exploratória e qualitativa. Do ponto de vista de seus objetivos, a pesquisa foi exploratória, quando elaborou o levantamento bibliográfico, a pesquisa documental e a definição do protocolo de pesquisa com suas diferentes variáveis para posteriormente analisar a realidade das cidades pesquisadas (Gil, 1999). No que diz respeito à forma da abordagem do problema, essa pesquisa foi qualitativa, pois descreveu as questões dinâmicas dos planos e planejamentos municipais, dos sistemas de informação e recursos da tecnologia da informação e da gestão, por meio de um survey em 52 cidades. Contextualizadas desde a fundamentação teórica até a avaliação do estado da arte dos temas em questão. Dessa forma, foram utilizados fenômenos qualitativos descritos e suas diversas variáveis, não necessariamente traduzidas somente em números quantitativos ou em processos estritamente metódicos (Nachmias e Nachmias, 1987). 
A segunda fase da pesquisa contemplou principalmente as abordagens descritiva e quantitativa e o estudo de caso nas 14 cidades. No tocante aos seus objetivos, foi descritiva quando descreveu a análise das variáveis que estabeleceram as relações entre os planos e planejamentos municipais, os sistemas de informação e os recursos da tecnologia da informação e a gestão de 14 cidades. E também na observação da real experiência quando da realização do estudo de caso nas 14 cidades, abordando os aspectos de descrição, registro, análise e interpretação das variáveis constantes no protocolo da pesquisa (Marconi e Lakatos, 1996). Quanto à forma da abordagem do problema, a pesquisa teve sua pequena vertente quantitativa, de caráter interpretativo, a partir da análise das variáveis das cidades pesquisadas (Gil, 1999). A segunda fase da pesquisa evidenciou o estudo de caso em 14 pequenas cidades gaúchas explorando fenômenos com base em diferentes ângulos (Roesch, 1999; Yin, 1994).

Essa pesquisa mesclou abordagens justificadas pelo ecletismo e integração de métodos de pesquisa indissociáveis (Nachmias e Nachmias, 1987; Vergara, 2005).

\subsection{Fases das pesquisas}

A metodologia da pesquisa foi dividida em duas fases para que seus dois objetivos fossem alcançados, onde foram trabalhados determinados passos (preparação para a pesquisa; fundamentação teórica; organização para o estudo de caso; análise e documentação) os quais definiram os objetivos, as atividades elaboradas e os resultados auferidos.

Com a primeira fase realizada foi possível mostrar a importância e necessidade dos planos e planejamentos municipais, dos sistemas de informação e recursos da tecnologia da informação e da gestão de 52 cidades, fundamentando e definindo as variáveis para a integração desses construtos. O período de realização dessas atividades foi durante o ano de 2004 e o primeiro semestre de 2005.

A segunda fase da pesquisa enfatizou a realização de um estudo de caso em 14 pequenas cidades gaúchas para mostrar as relações propostas. O período de realização dessas atividades foi durante o segundo semestre de 2005 e início de 2006.

Ambas as fases são partes integrantes de uma pesquisa mais ampla que estuda a práticas das aplicações dos sistemas de informação e dos recursos da tecnologia da informação e suas contri- 
buições no planejamento e na gestão estratégica de cidades brasileiras e internacionais. Essas atividades fazem parte de um projeto de pesquisa de um programa de mestrado.

\subsection{Protocolo da pesquisa}

O delineamento da pesquisa determina o que deve ser pesquisado e o que dever ser analisado (Roesch, 1999: 126). Para que a análise dos dados levantados fosse viabilizada, foi necessário pesquisar e definir variáveis (ou critérios) para direcionar e interpretar os seus resultados. Essas variáveis são partes fundamentais do protocolo da pesquisa. Nesse protocolo foi estabelecida uma relação entre os construtos e respectivas variáveis com os autores que fundamentaram as variáveis e respectivas perguntas constantes nos roteiros utilizados na pesquisa. Cada variável continha perguntas, as quais determinaram a forma de medição.

Os instrumentos de coleta de dados da pesquisa foram: roteiro de levantamento de dados; roteiro de entrevistas; entrevistas; e observações assistemáticas. Os roteiros foram organizados e estruturados a partir da fundamentação teórica e das experiências vivenciadas dos pesquisadores. Foram cuidadosamente analisados por professores, pesquisadores e profissionais da área, para corroborar com sua confiabilidade e validabilidade. Estavam estruturados em: dados da cidade; identificação do respondente; frases ou perguntas fechadas e abertas, divididas nos construtos do protocolo da pesquisa. A observação assistemática se consistiu no registro de fatos da realidade, elaborada de maneira espontânea conforme os fatos e atividades de pesquisa ocorreram (Marconi e Lakatos, 1996; Gil, 1999).

A unidade de observação para as entrevistas foi constituída pelos integrantes das equipes internas de servidores públicos municipais das cidades, mais direcionadas às Secretarias Municipais de Planejamento e às Unidades de Planejamento e de Informática. A amostra do estudo de caso foi definida em função da acessibilidade por conveniência (Gil, 1999, p. 104).

O protocolo da pesquisa foi dividido em construtos: unidade ou departamento da tecnologia da informação ou informática; hardware; software; sistemas de telecomunicação; gestão de dados e informação; sistemas de informação; planos e planejamentos municipais; e contribuições e alinhamento dos sistemas de informação e da tecnologia da informação aos planos e planejamentos municipais. 
Cada um dos construtos foi desmembrado em variáveis. A Unidade ou Departamento da Tecnologia da Informação ou Informática com as variáveis: subordinação da unidade; existência de instituto externo à prefeitura; número de servidores públicos municipais; número de prestadores de serviços; percentual (ou valores) de arrecadação destinado à tecnologia da informação; treinamentos de tecnologia da informação para os técnicos da tecnologia da informação; e treinamentos de tecnologia da informação para os usuários (servidores públicos municipais). O Hardware com as variáveis: número de computadores na prefeitura, secretarias municipais e demais órgãos municipais; e tipos de computadores. O Software com as variáveis: sistema operacional; linguagens de programação; e outras tecnologias. Os Sistemas de Telecomunicação com as variáveis: software de rede; e tipo de cabeamento e equipamentos. A Gestão de Dados e Informação com as variáveis: cópias dos dados (backup); recuperações dos dados (restore); senhas para acesso aos dados dos sistemas; e níveis de navegação nas informações dos sistemas. Os Sistemas de Informação com as variáveis: sistemas municipais informatizados; integração dos sistemas municipais; sistemas gerenciais e estratégicos; e sistemas de governo eletrônico (e-gov) ou portal municipal. Os Planos e Planejamentos Municipais com as variáveis: Plano Plurianual Municipal; Plano Diretor Municipal; Planejamento Estratégico Municipal; Planejamento Estratégico dos Sistemas de Informação e da Tecnologia da Informação; Planejamento dos Recursos Humanos (servidores públicos municipais); Integração ou alinhamento entre os planejamentos e planos municipais; e fatores que sustentam a integração entre os planejamentos e planos municipais. E finalmente o construto Contribuições e Alinhamento dos Sistemas de Informação e da Tecnologia da Informação aos planos e planejamentos municipais com a variável: formas de contribuição.

Cada uma dessas variáveis possui seus respectivos autores fundamentados.

\section{As cidades envolvidas da região do médio alto uruguai do estado do rio grande do sul e as suas peculiaridades}

Foram descritas algumas características da regionalização no Estado do Rio Grande do Sul e as especificidades da Região do Médio Alto Uruguai e destacados, de forma sucinta, alguns aspectos e indicadores econômicos, sociais, históricos e culturais. 


\subsection{O Brasil e suas regióes}

As Regiões do Brasil são divisões que têm caráter legal e que foram propostas pelo Instituto Brasileiro de Geografia e Estatística (IBGE, 2007) em 1969. O IBGE levou em consideração apenas aspectos naturais na divisão do país, como clima, relevo, vegetação e hidrografia; por essa razão, as regiões também são conhecidas como «regiões naturais do Brasil». Há uma pequena exceção com relação à região Sudeste, que foi criada levando-se parcialmente em conta aspectos humanos (desenvolvimento industrial e urbano). Cada uma dessas divisões é composta por uma região, e as regiões brasileiras são: Centro-Oeste; Nordeste; Norte; Sudeste; e Sul. Região Centro-Oeste, que se compõe dos estados: Goiás, Mato Grosso e Mato Grosso do Sul e do Distrito Federal. Possui um território de $1.604 .852 \mathrm{~km} 2$ (18,9\% do território nacional). Sua população é de cerca de 12 milhões de habitantes. Região Nordeste, que se compõe dos estados: Maranhão, Piauí, Ceará, Rio Grande do Norte, Paraíba, Pernambuco, Alagoas, Sergipe e Bahia. Possui um território de $1.556 .001 \mathrm{~km} 2$ (18,2\% do território nacional), dentro dos quais está localizado o Polígono das secas. Sua população é pouco superior a 50 milhões de habitantes. Região Norte, que se compõe dos estados: Acre, Amazonas, Roraima, Rondônia, Pará, Amapá e Tocantins. Possui um território de 3.851 .560 km2 (45,2\% do território nacional), e uma população pouco superior a 14 milhões de habitantes - o que faz dela a região com menor densidade demográfica. Região Sudeste, que se compõe dos estados: Minas Gerais, Espírito Santo, Rio de Janeiro e São Paulo. Possui um território de $927.286 \mathrm{~km} 2$ (10,6\% do território nacional). Sua população é de cerca de 77 milhões de habitantes. Região Sul, que se compõe dos estados: Paraná, Santa Catarina e Rio Grande do Sul. Possui um território de $575.316 \mathrm{~km}^{2}$ (6,8\% do território nacional) e sua população é de mais de 26 milhões de habitantes.

\subsection{A regionalização no Estado do Rio Grande do Sul}

No contexto da descentralização, participação e regionalização deflagrada a partir da Constituição Federal de 1998 e da Constituição Estadual de 1989, foi propiciada uma participação maior da sociedade civil na definição das políticas de desenvolvimento. Assim, surgiram no Rio Grande do Sul os Conselhos Regionais de Desenvolvimento (Coredes) como uma nova proposta de re- 
gionalização e ação político-administrativa visando ao desenvolvimento. Segundo Siedenberg, Saad e Senger (2005: 212), os Coredes surgem no intuito de "promover o desenvolvimento regional harmônico e sustentável; integrar os recursos e as ações do governo na região; melhorar a qualidade de vida da população; distribuir de forma eqüitativa a riqueza produzida; estimular a permanência da população em sua região e preservar e recuperar o meio ambiente". Os Coredes configuram uma das principais instâncias de planejamento e desenvolvimento regional. Tais conselhos foram criados no Estado do Rio Grande do Sul por meio da Lei Estadual n.10.238/94 e constituem-se em fórum de discussão e decisão a respeito de políticas públicas e ações que fomentem o desenvolvimento com sustentabilidade. Sua missão é ser espaço plural e aberto de construção de parcerias sociais e econômicas, em nível regional, através da articulação política dos interesses locais e setoriais em torno de estratégias próprias e específicas de desenvolvimento para as regiões do Rio Grande do Sul.

Segundo Codemau (2005: 7) os objetivos dos COREDES são: formular e executar estratégias regionais, consolidando-as em planos estratégicos de desenvolvimento regional; avançar a participação social cidadã, combinando múltiplas formas de democracia direta com representação política; constituir-se em instância de regionalização das estratégias e das ações do Executivo, Legislativo e Judiciário, do Rio Grande do Sul, conforme estabelece a Constituição do Estado; avançar na construção de espaços públicos de controle social dos mercados e dos mais diversos aparelhos do Estado; conquistar e estimular a crescente participação social cidadã na definição dos rumos do processo de desenvolvimento; intensificar o processo de construção de uma organização social pró-desenvolvimento regional; difundir a filosofia e a prática cooperativa de se pensar e fazer o desenvolvimento regional em parceria. Os princípios que norteiam os trabalhos de organização e formulação de planos de desenvolvimento regional nos Coredes, segundo o Codemau (2005: 8), são: promoção de desenvolvimento regional; autonomia; pluralidade e identificação de consensos; confiança, cooperação e formulação de parcerias; integração, articulação e consolidação das identidades regionais; busca da regionalização das políticas de desenvolvimento; aumento permanente da representatividade e da organização e apoio à continuidade das políticas públicas de interesse regional. A missão, visão e princípios pré-estabelecidos 
pautam as atividades do Codemau (2005: 11) em: promover a participação de todos os segmentos da sociedade regional no diagnóstico de suas necessidades e potencialidades para a formulação e implementação das políticas de desenvolvimento integrado da região; manter espaço permanente de participação democrática, resgatando a cidadania, através da valorização da ação política; constituir-se em instância de regionalização do orçamento do Estado, conforme estabelece o Art. 149, parágrafo 8 da Constituição do Estado; orientar e acompanhar de forma sistemática o desempenho das ações do Governo Estadual e Federal na região; respaldar as ações do Governo do Estado na busca de maior participação nas decisões nacionais.

Atualmente, existem 24 Coredes constituídos no Estado. Entre eles está o Coredes Médio Alto Uruguai, também chamado de Codemau, o qual abrange a área dos municípios objeto dessa pesquisa e compreende os municípios do extremo norte do Estado do Rio Grande do Sul. Faz divisa com o Estado de Santa Catarina (Figura 1), possui 173.080 habitantes, distribuídos numa área de $5.258,0 \mathrm{~km}^{2}$, configurando uma densidade demográfica de $32,91 \mathrm{hab} / \mathrm{km}^{2}$ (Fee, 2004). Configura algo em torno de $2 \%$ do total do território gaúcho. Nesse espaço estão distribuídos 30 (ou $6 \%$ dos 496) municípios gaúchos. Em função destas proporções decorre a existência de municípios de pequeno porte no que diz respeito à sua dimensão geográfica.

A população das cidades envolvidas (ou municípios) nesta análise representa, em conjunto, 61,18\% dos habitantes da Região do Médio Alto Uruguai, o que configura uma amostra razoável de investigação. A principal característica econômica é a predominância de minifúndios e agricultura familiar. A menor cidade possui 2.365 habitantes e a maior possui 12.818 habitantes. O número médio de servidores públicos municipais é de 196,1 pessoas. O valor médio de arrecadação anual é de R $\$$ 4.159.270,57.

O Codemau iniciou suas atividades em 1992, abrange $30 \mathrm{mu}-$ nicípios e soma uma população de 173.080 habitantes (FEE, 2004). Sua sede está localizada junto a URI-Universidade Regional Integrada do Alto Uruguai e das Missões em Frederico Westphalen, a qual está dotada de logística, equipe de assessores e colaboradores para atender à missão e aos objetivos e demandas regionais anteriormente explicitadas.

Segundo Bernardes (1997), o Rio Grande do Sul foi a derradeira parte do Brasil a ser povoada e, dentro do Rio Grande do 
Figura I

Mapa da região do Médio Alto Uruguai do Estado do Rio Grande do Sul

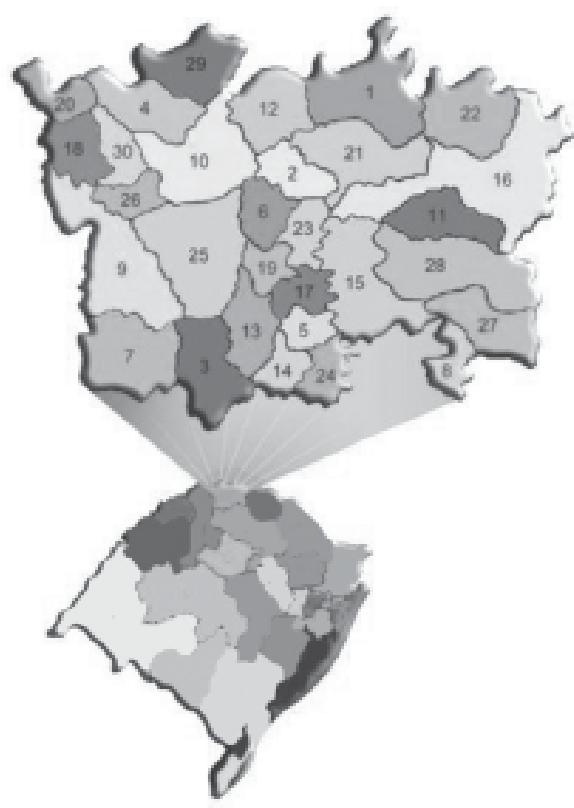

$$
\begin{aligned}
& \text { 01. Alpestre } \\
& \text { 02. Ametista do Sul } \\
& \text { 03. Boa Vista das Missões } \\
& \text { 04. Caiçara } \\
& \text { 05. Cerro Grande } \\
& \text { 06. Cristal do Sul } \\
& \text { 07. Dois Irmãos das Missões } \\
& \text { 08. Engenho Velho } \\
& \text { 09. Erval Seco } \\
& \text { 10. Frederico Westphalen } \\
& \text { 11. Gramado dos Loureiros } \\
& \text { 12. Iraí } \\
& \text { 13. Jaboticaba } \\
& \text { 14. Lajeado do Bugre } \\
& \text { 15. Liberato Salzano } \\
& \text { 16. Nonoai } \\
& \text { 17. Novo Tiradentes } \\
& \text { 18. Palmitinho } \\
& \text { 19. Pinhal } \\
& \text { 20. Pinheirinho do Vale } \\
& \text { 21. Planalto } \\
& \text { 22. Rio dos Indios } \\
& \text { 23. Rodeio Bonito } \\
& \text { 24. Sagrada Familia } \\
& \text { 25. Seberi } \\
& \text { 26. Taquaruçu do Sul } \\
& \text { 27. Três Palmeiras } \\
& \text { 28. Trindade do Sul } \\
& \text { 29. Vicente Dutra } \\
& \text { 30. Vista Alegre }
\end{aligned}
$$

Fonte: Codemau, 2005.

Sul, o extremo norte foi a última região que despertou interesse pela exploração econômica, basicamente em função do relevo e da vegetação oferecer maiores dificuldades de ocupação do território. Isso explica porque a região do Médio Alto Uruguai foi considerada, por um bom tempo, como uma das regiões mais atrasadas do Rio Grande do Sul. Apesar de essa realidade estar se alterando, ainda há um longo caminho para trilhar, pois existem entraves consideráveis. Contudo, muitos avanços aconteceram ao longo dos anos e pode-se considerar que grande parte são conquistas resultantes da articulação da própria sociedade e das parcerias estabelecidas entre as instituições de ensino. Principalmente a Universidade Regional Integrada do Alto Uruguai e das Missões (URI), as Prefeituras Municipais, o Codemau-Conselho de Desenvolvimento do Médio Alto Uruguai, as Câmaras de Vereadores, as Organizações Governamentais e Não-Governamentais, o Governo do Estado e o Governo Federal. Através de programas governamentais, várias ações, visando ao desenvolvimento regional, estão sendo realizadas com a participação 
de diferentes segmentos, estimulando a cooperação e a integração entre os municípios da região.

Em comparação com outras regiões do Estado, constata-se que a região do Médio Alto Uruguai possui um baixo dinamismo comercial e industrial e oferece escassas oportunidades de trabalho nestes dois setores, ocasionando a migração de pessoas para áreas industrializadas do Estado do Rio Grande do Sul e até mesmo para outras regiões do país. Contudo, a região vem se destacando pela crescente exploração da diversidade de bens naturais. Há um grande potencial em águas minerais, pedras preciosas, lama medicinal, matas, cachoeiras e rios. Com base nesse contexto, o CODEMAU vem promovendo iniciativas de fomento ao turismo na região, principalmente nos municípios de Ametista do Sul, Iraí, Frederico Westphalen e Vicente Dutra.

\subsection{Indicadores das cidades}

Dos quatorze municípios selecionados para o estudo, nenhum apresenta o indicador de desenvolvimento sócio econômico (IDESE) acima da média do estado do Rio Grande do Sul durante os anos avaliados (1991, 2000, 2001, 2002, 2003), que em 2003 obteve um IDESE de 0,757 (Quadro 6). Como o indicador de desenvolvimento sócio-econômico (IDESE) é uma média aritmética dos indicadores relacionados à educação, renda, saneamento e saúde, considera-se que seus pesos são proporcionais. Para cada indicador, os 496 municípios do Rio Grande do Sul são ordenados de forma decrescente, são divididos em quartis conforme o seguinte quadro:

Quadro 1

Quartil referencial

\begin{tabular}{crc}
\hline Quartil & \multicolumn{1}{c}{ de } & até \\
\hline 1 & 1 & 124 \\
2 & 125 & 248 \\
3 & 249 & 372 \\
4 & 373 & 496 \\
\hline
\end{tabular}

Neste sentido, os municípios analisados, considerando o IDESE, dois (Vista Alegre e Rodeio Bonito) estão no segundo quartil; três no terceiro quartil (Pinhal, Nonoai e Cerro Grande) e; nove no quarto quartil (Dois Irmãos das Missões, Seberi, Liberato Salzano, Pinheirinho do Vale, Novo Tirandentes, Alpestre, Jaboticaba, Três Palmeiras e Palmitinho). 


\subsubsection{Educação}

Em 1991, somente dois municípios, Rodeio Bonito (0,773) e Seberi $(0,768)$, estavam com o indicador de educação acima da média estadual $(0,765)$, todos os demais municípios estavam com o indicador educação abaixo. Em 2003, os dois municípios mantiveram suas posições na região do MAU, com a inclusão do município de Novo Tiradentes na terceira posição. No entanto, houve uma pequena melhora em todos os municípios, mas não de forma suficiente, sendo que todos, com exceção de Rodeio Bonito, foram rebaixados no posicionamento em relação aos demais municípios do Estado do Rio Grande do Sul (Quadro 2). O Quadro 2 representa a evolução do indicador Educação e, considerando o indicador para todos os municípios do estado, Rodeio Bonito obteve um desempenho excepcional, pois em 1991 estava na nonagésima primeira colocação e em 2003 saltou para quinto lugar. Esta melhora significativa não encontra paralelos nos demais indicadores e não são explicados por eles. Apesar da melhora do indicador em todos, com destaque para os municípios de Rodeio Bonito, que saltou da nonagésima primeira posição para quinta posição em 2003, e de Novo Tiradentes, que saiu da posição 275 em 2000, para 222 em 2003, Palmitinho ficou na posição 495, entre os 496 municípios do Rio Grande do Sul. O que se percebe é que o indicador de Educação mantém tendência de crescimento nos períodos observados.

\subsubsection{Renda}

Entre 1991 e 2003, os municípios Vista Alegre, Dois Irmãos das Missões, Seberi, Nonoai, Alpestre e Rodeio Bonito, tiveram seus indicadores melhorados, inclusive subiram no posicionamento entre os demais municípios do Rio Grande do Sul (Quadro 3). No mesmo período, os municípios Pinhal, Três Palmeiras, Jaboticaba, Cerro Grande, Liberato Salzano, Pinheirinho do Vale, Novo Tiradentes, melhoraram o indicador, porém, pioraram seu posicionamento em relação aos demais municípios do Rio Grande do Sul. Palmitinho foi exceção, pois seu indicador de Renda piorou, rebaixando sua posição de 310 para 486. O indicador de Renda obteve, em 2003, um crescimento anual (1,45\%) em relação aos anos anteriores, sendo que, junto com o indicador de Educação, foi o responsável pela melhora do IDESE neste ano. 
Economía, Sociedad y Territorio, vol. viII, núm. 28, 2008, 879-919

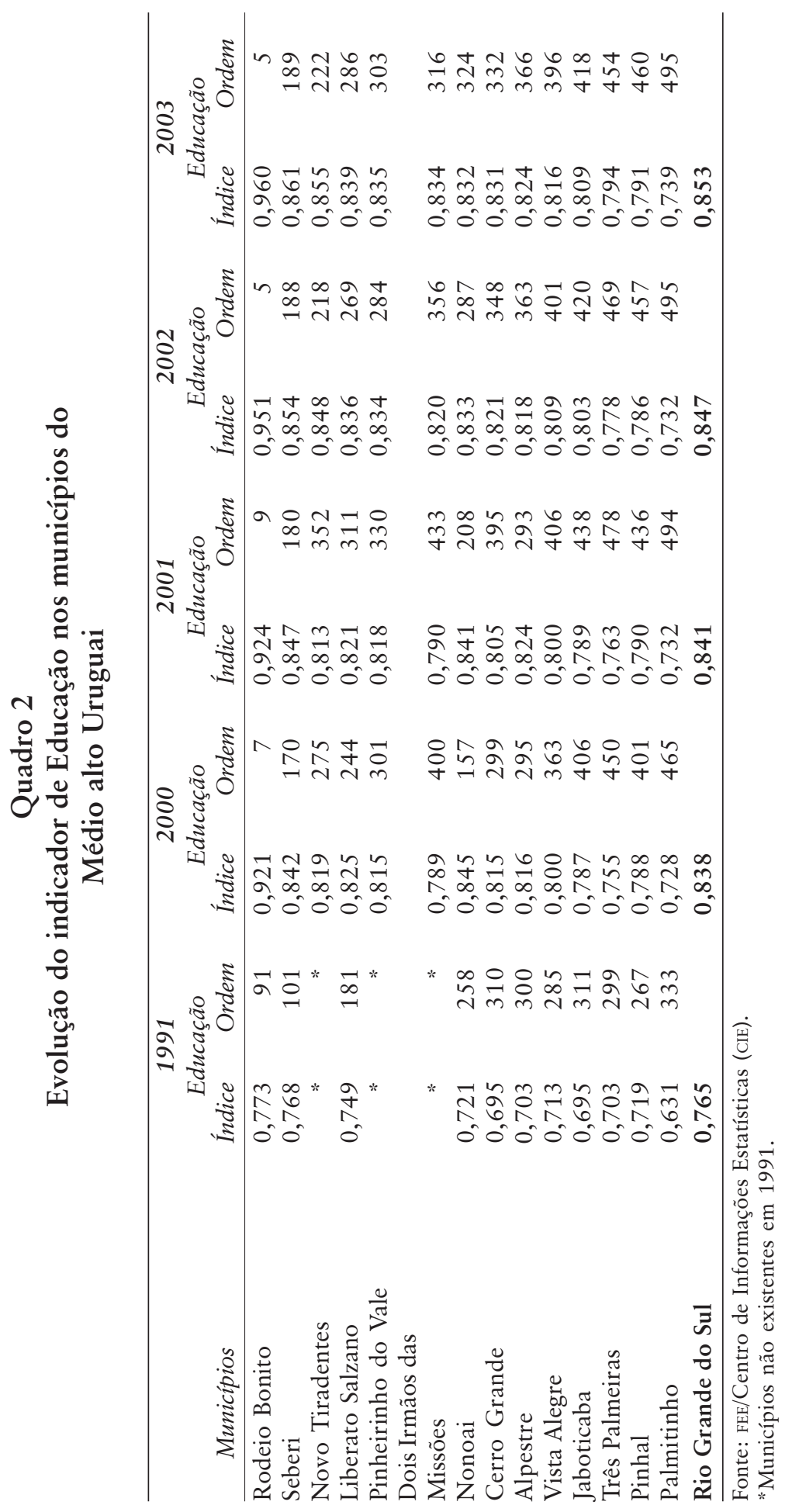

est28_3.pmd

24/11/2008, 04:00 p.m. 


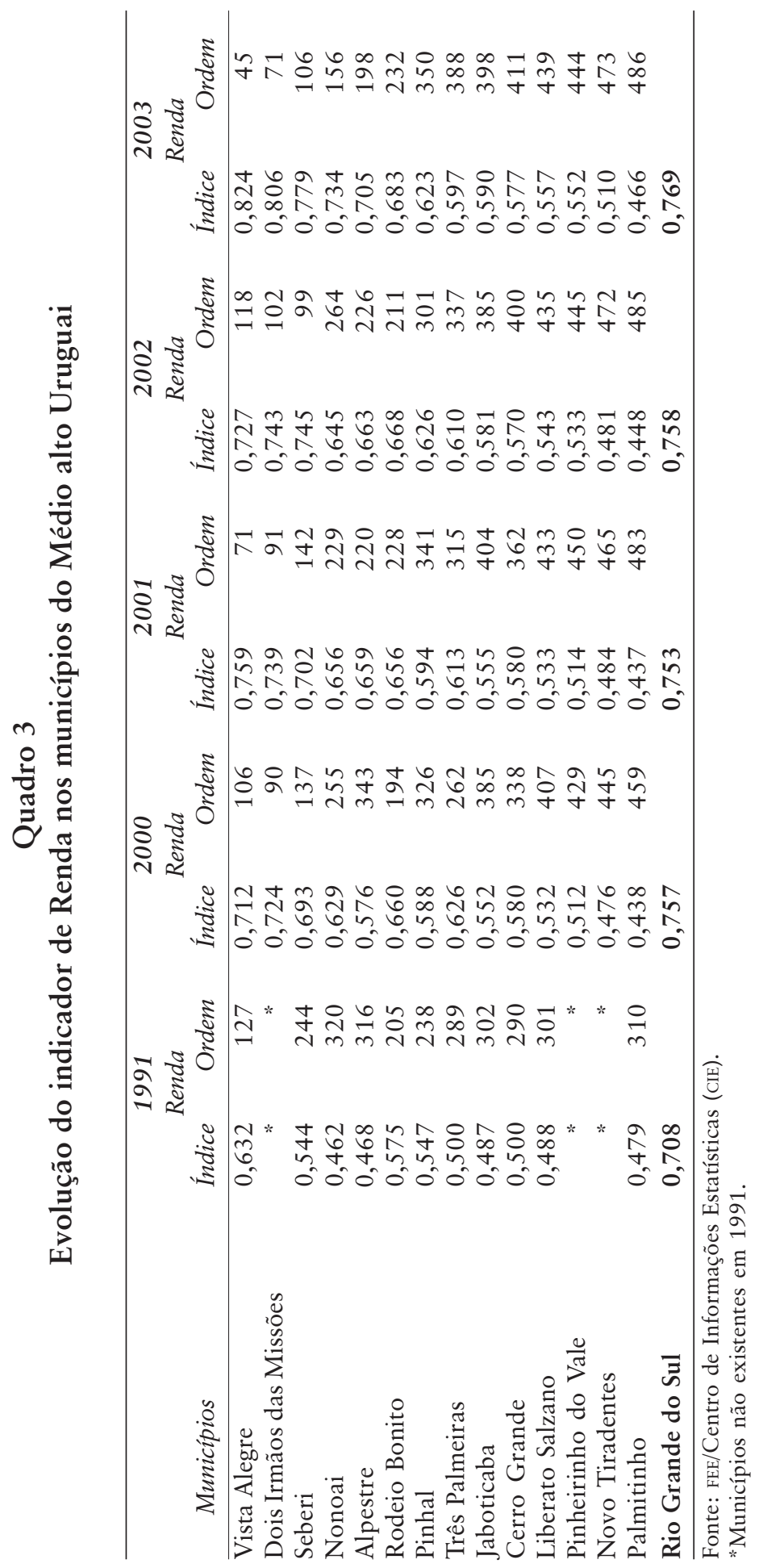




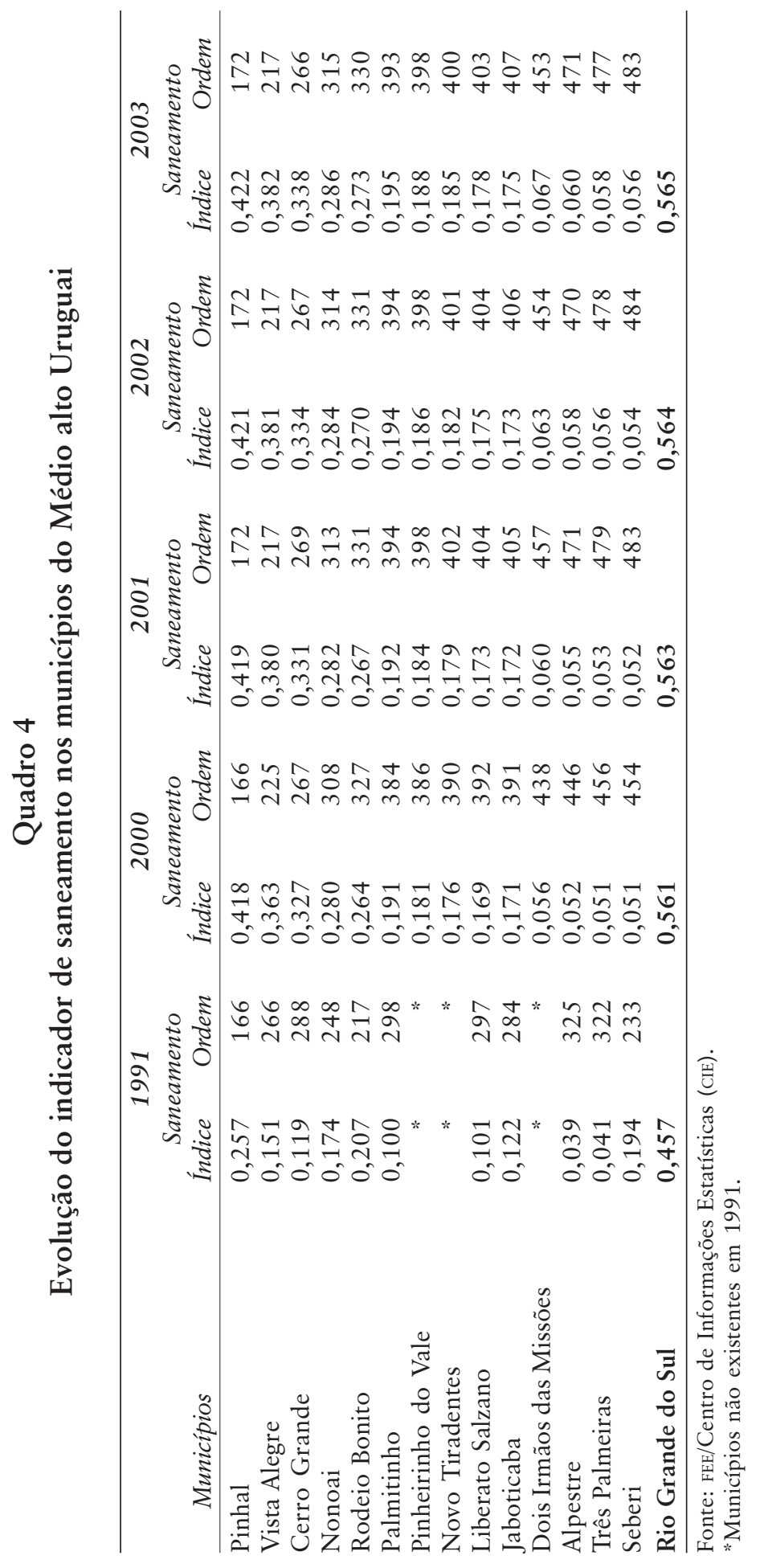




\subsubsection{Saneamento}

Com exceção de Seberi, os demais municípios melhoraram seus indicadores de saneamento. Porém, esta melhora não foi significativa, posicionando os municípios da região avaliada entre os piores do Rio Grande do Sul (Quadro 4).

\subsubsection{Saúde}

Para este indicador, todos os municípios obtiveram ligeira queda e pioraram seus posicionamentos em relação aos demais municípios do Rio Grande do Sul (Quadro 5), apesar da melhora dos indicadores de Educação e Renda.

\subsubsection{Idese}

Neste indicador, apesar de todos os municípios da região terem melhorado, somente Vista Alegre melhorou seu posicionamento em relação aos demais municípios do Rio Grande do Sul. Os outros pioraram (Quadro 6). Não foi possível correlacionar os indicadores, embora a melhoria, ainda que modesta nos indicadores de educação e renda, não colaboraram para uma melhora no indicador de saúde, o que parece ser um descompasso entre o ensino formal medido pelo indicador e a cultura local, que reflete os usos e costumes dos moradores da região.

\section{Análises dos sistemas, tecnologia da informação e planejamentos municipais}

As referidas análises contemplam o estudo de caso nas 14 pequenas cidades, anteriormente caracterizadas, considerando: unidade ou departamento da tecnologia da informação ou informática; os recursos da tecnologia da informação; os sistemas de informação; os planos e planejamentos municipais; e as contribuições e alinhamento dos sistemas de informação e da tecnologia da informação aos planos e planejamentos municipais.

\subsection{Análise da unidade da tecnologia da informação}

No que tange a variável subordinação da Unidade da Tecnologia da Informação ou Departamento de Informática, em 10 municípios $(71,4 \%)$ não existia essa unidade na prefeitura. Em 2 muni- 


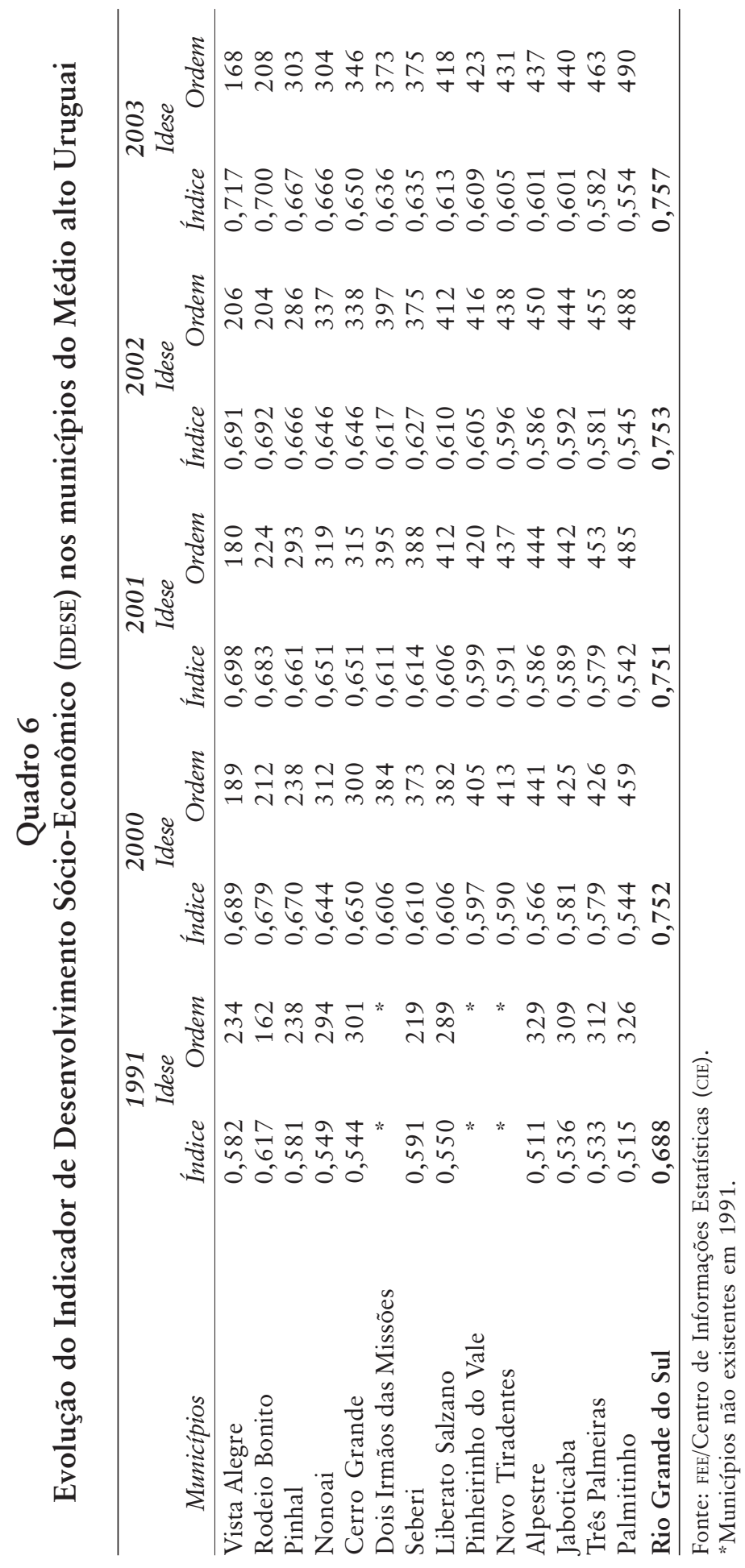


cípios estava subordinada ao Gabinete do Prefeito e em outros 2 municípios à Secretaria de Administração e à Secretaria de Planejamento, respectivamente.

Em nenhum município existia um Instituto Externo à prefeitura para desenvolver as atividades de tecnologia da informação.

Quanto ao número de servidores públicos municipais na Unidade da Tecnologia da Informação, em 10 prefeituras $(71,4 \%)$ não existia servidores públicos municipais nessa unidade. Em 3 prefeituras existia apenas 1 servidor responsável por essa unidade e em 1 prefeitura existiam 2 servidores nessa unidade.

Com relação ao número de prestadores de serviços na Unidade de Tecnologia da Informação (externos à prefeitura) em 5 prefeituras $(35,7 \%)$ tinha apenas 1 prestador. Em 6 prefeituras existiam 2 prestadores, em 1 prefeitura 3 prestadores e em outras 2 prefeituras existiam 4 prestadores de serviço.

O valor da arrecadação destinado aos recursos da tecnologia da informação não eram destinados para 5 prefeituras $(35,7 \%)$. Para outras 6 prefeituras esse valor estava entre 20 e 35 mil reais anuais. E para outras 3 prefeituras, respectivamente, 4, 60 e 100 mil reais por ano para investimentos em tecnologia da informação no município.

Os treinamentos de tecnologia da informação para os técnicos da unidade da tecnologia da informação não eram oferecidos em 9 prefeituras (64,2\%). Em 3 prefeituras eram oferecidos treinamentos para os sistemas (pacotes externos dos prestadores de serviços). Em 2 prefeituras eram treinados nos recursos básicos de informática e nos sistemas externos.

A última variável de pesquisa desse construto diz respeito aos treinamentos de tecnologia da informação para os usuários (servidores públicos municipais), os quais não eram elaborados em 8 prefeituras $(57,1 \%)$. Em 5 prefeituras eram oferecidos treinamentos nos recursos básicos de informática e nos sistemas (pacotes externos dos prestadores de serviços). E em 1 prefeitura eram treinados apenas nos sistemas externos dos prestadores de serviços.

Algumas considerações podem ser descritas sobre o construto Unidade da Tecnologia da Informação. O alto percentual de inexistência dessa unidade é correlacionado com a necessidade da utilização de empresas prestadoras de serviços de sistemas externos e como conseqüência, a substituição de servidores públicos municipais por prestadores de serviços nas atividades da tecnologia da informação. Também chama a atenção o percen- 
tual de prefeituras que não destinam recursos financeiros para essa unidade, e, por outro lado, o baixo percentual de treinamentos para capacitar os seus recursos humanos.

\subsection{Análise dos recursos da tecnologia da informação}

No que diz respeito a variável número de computadores (hardware) na prefeitura, secretarias municipais e demais órgãos municipais, a média é de 23 microcomputadores. Em 8 municípios esse número fica entre 10 e 22 equipamentos, em 6 municípios entre 30 e 40 equipamentos.

Todos os municípios possuíam apenas microcomputadores, incluindo os computadores servidores em rede.

Com relação ao sistema operacional, o software utilizado na prefeitura, secretarias municipais e demais órgãos em 10 municípios (71,4\%) era o Windows. Em 4 municípios era o Windows e Linux.

Foram identificadas 9 diferentes linguagens de programação nos municípios. A mais utilizada era o Cobol (em 6 prefeituras, 42,8\%). E em outras 4 prefeituras: Access; Delphi; e Clipper.

Quanto às outras tecnologias que mereçam destaque nos municípios, em apenas 1 prefeitura foram citados os recursos de Wirelles para Monitoramento de Tráfego e Geoprocessamento. Nas demais prefeituras não foram destacadas outras tecnologias da informação em utilização.

Com relação aos sistemas de telecomunicação, o software de rede utilizado na prefeitura, secretarias municipais e demais órgãos de todos os municípios (100\%) era o Windows.

O tipo de cabeamento e equipamentos utilizados para telecomunicação em 7 municípios (50\%) era o coaxial, sendo que em 6 prefeituras eram utilizadas também as antenas de rádio. Em outros 7 municípios eram utilizados o par trançado, sendo que em 3 com antenas de rádio e em 1 com Wirelles.

A gestão de dados e informação no tocante às formas de cópias (backups) utilizadas na prefeitura, secretarias municipais e demais órgãos municipais, em 4 municípios $(28,5 \%)$ essa atividade era manual. Nos outros 10 municípios as cópias eram feitas via sistema, sendo que em 6 municípios os dados eram armazenados em servidores e em outros 6 municípios eram guardados em meios magnéticos. 
A forma de recuperação de dados (restores) era elaborada manualmente em 12 municípios $(85,7 \%)$ e somente quando necessário. Nos outros 2 municípios era elaborada via sistema com comandos específicos.

As senhas para acesso aos dados dos sistemas em 7 municípios $(50 \%)$ eram definidas pelo sistema por usuário e departamento. Em outros 7 municípios não existiam senhas, o sistema era aberto a todos os usuários (servidores públicos municipais).

A última variável de pesquisa desse construto, os níveis de navegação nas informações dos sistemas, em 5 municípios $(35,7 \%)$ eram determinados pelo sistema por usuário e departamento. Em outros 9 municípios não existiam níveis de navegação, o sistema era aberto a todos os usuários (servidores públicos municipais).

As considerações desse construto estão relacionadas com a inexistência de grandes computadores nos municípios e com o uso enfatizado de software proprietário (Windows) em oposição ao software "aberto ou livre" (Linux). As linguagens de programação utilizadas retratam a alta dependência dos prestadores de serviços de sistemas (pacotes externos), a inexistência de tecnologias dominadas pelas prefeituras e a precária estrutura de gestão de dados e informação.

\subsection{Análise dos sistemas de informação}

No que concerne a variável sistemas municipais informatizados, foram identificados 12 diferentes aplicativos nos municípios. Os sistemas mais presentes nas prefeituras foram: Arrecadação e Tributação; Contabilidade; e Folha de Pagamento. Esses sistemas estavam presentes em 14, 10 e 10 municípios, respectivamente. E entre 9 e 4 municípios estavam presentes os sistemas: Educação; Saúde; Agricultura (rural); Contas públicas (financeiro); Frotas; Compras (e licitação); Estoque (materiais); e Patrimônio.

Do ponto de vista de integração, em apenas 5 municípios $(35,7 \%)$ os sistemas municipais eram integrados automaticamente (via software de pacotes externos das empresas prestadoras de serviços). Em 6 municípios os sistemas municipais eram parcialmente integrados, ou seja, apenas partes dos softwares em uso eram integrados automaticamente. Em outros 3 municípios os sistemas municipais não eram integrados, nem parcialmente.

Os sistemas municipais gerenciais e estratégicos não foram identificados em nenhum município. Em 4 municípios (28,7\%) 
foram identificados apenas relatórios gerenciais gerados dos sistemas municipais nas prefeituras.

A última variável de pesquisa desse construto diz respeito aos sistemas de governo eletrônico (e-gov) ou portal municipal, os quais não foram identificados em 10 municípios (71,4\%). Em 4 municípios o site tinha sido desenvolvido em parceria com um fornecedor desse tipo de serviço e não via governo (www.rs.gov.br).

Nesse construto podem ser relatadas algumas considerações. $\mathrm{O}$ alto percentual de não integração sistêmica reitera a dependência dos prestadores de serviços de sistemas para manutenção dos mesmos. Quase total inexistência de informações ou indicadores gerenciais ou estratégicos nos municípios dificultando as decisões dos gestores. Nenhum município tinha um portal da cidade, dificultando a divulgação e disseminação eletrônica de informações municipais e compartilhamento de conhecimentos dos munícipes.

\subsection{Análise dos planos e planejamentos municipais}

A primeira variável é uma exigência legal para todos os municípios. Dessa forma, o Plano Plurianual Municipal (PPAM) foi identificado em todos os municípios. Em 9 municípios $(64,2 \%)$ foi convencionalmente elaborado com audiências públicas e já estava aprovado pela Câmara Municipal. Em 5 municípios tinha sido elaborado a partir do Ppam anterior, com base no Programa de Governo do prefeito atual e estava aprovado pela Câmara Municipal.

O Plano Diretor Municipal (PDM) não existia em todos os municípios, apesar de que em 2 municípios o PDM estava em processo de início de elaboração (com apoio de consultoria externa).

O Planejamento Estratégico Municipal (PEM) não existia em todos os municípios, apesar de que em 2 municípios foram elaborados projetos parciais que tinham características estratégicas.

O Planejamento Estratégico dos Sistemas de Informação e da Tecnologia da Informação (PESITI) não existia em todos os municípios, apesar de que em 3 municípios existiam projetos parciais com características pertinentes.

O Planejamento dos Recursos Humanos (PRH) para os servidores públicos municipais não foi identificado em nenhum município. Apesar de que em 2 municípios existiam projetos parciais com levantamento de pessoal necessário para os órgãos e secretarias municipais, elaborados em conjunto com o Setor de Recursos Humanos da prefeitura. 
Quanto ao alinhamento ou integração entre os planos e planejamentos municipais, como os municípios não possuíam todos esses projetos, esse alinhamento não existia totalmente. Em 2 municípios, considerando apenas PPAM e PEM, eram parcialmente alinhados.

A última variável desse construto (fatores que sustentam o alinhamento ou a integração entre os planos e planejamentos municipais) foi identificada apenas nos 2 municípios que tinham o PPAM e o PEM parcialmente alinhados. Os fatores integradores foram: planejamentos e orçamentos participativos; humanos; políticos; sistêmicos; e tecnológicos. O primeiro fator teve 2 citações e os demais apenas 1 citação.

Determinadas considerações podem ser expostas sobre esse construto. Como é exigido por lei, o ppam foi elaborado em todos os municípios. Apesar de não obrigatório para os municípios pesquisados, em 2 municípios o PDM estava sendo iniciado. O PEM tinha sido elaborado parcialmente em apenas 2 municípios. $\mathrm{O}$ PESITI e PRH não tinham sido elaborados em todos os municípios. Observa-se que o planejamento não é um habitual instrumento de gestão dos municípios, muito menos de participação dos munícipes na condução das cidades.

\subsection{Contribuições e alinhamento da tecnologia da informação}

Quanto a variável forma de contribuição dos sistemas de informação e da tecnologia da informação, em 4 municípios $(28,5 \%)$ não foram citadas contribuições, ou seja, alegaram que esses recursos não contribuem em nada nos planos, planejamentos e gestão municipais.

Nos demais 10 municípios foram citados as contribuições. A maior contribuição (7 citações) está relacionada ao controle interno, seguidas da avaliação dos dados municipais, apoio à gestão municipal, ao auxílio à prestação dos serviços municipais, com 4, 3 e 3 citações respectivamente. Também aparecem com 2 e 1 as respectivas citações: redistribuição dos recursos humanos, materiais e financeiros; e com os sistemas de informação e a tecnologia da informação como instrumentos de integração na prefeitura.

E finalmente quanto ao percentual de alinhamento entre a tecnologia da informação e Plano Plurianual Municipal, as respostas foram: $20 \% ; 30 \% ; 30 \% ; 50 \% ; 60 \%$; 70\%; 70\%; 70\%; $70 \% ; 75 \% ; 80 \% ; 80 \% ; 85 \%$; e $90 \%$. A média foi de $62,8 \%$. Es- 
ses percentuais foram justificados pelos respondentes com os seguintes fatores (e ocorrências) que sustentam o referido alinhamento: dados e informações disponíveis (8); rapidez nas tarefas e agilidade dos processos (7); confiabilidade nas informações (6); qualidade e agilidade nos trabalhos (5); integração entre os dados das diversas secretarias (5); segurança nas informações (3); recursos tecnológicos disponíveis (2); suporte para prestação de contas (1); e suporte para elaboração de programas e projetos (1 ocorrência).

A primeira consideração desse construto da pesquisa está relacionada com o alto percentual declarado $(71,4 \%)$ que os sistemas de informação e a tecnologia da informação contribuem com os planos e planejamentos municipais e com a gestão das cidades. A segunda, está relacionada com os percentuais declarados de alinhamento, relativamente altos na média. Isso é relevante em pequenos municípios (ou cidades) que possuem restritos recursos tecnológicos.

\section{Conclusão}

As dificuldades nas cidades (ou municípios) de caráter sociais, ambientais, culturais, políticas, econômicas, financeiras e competitivas são inquestionáveis e foram vivenciadas nessa pesquisa. Tais dificuldades requerem dos gestores das cidades instrumentos de planejamento participativo para atender as exigências legais e para satisfazer as demandas de qualidade de vida mais adequada aos cidadãos. Para tanto, os planos e planejamentos municipais tornam-se inexoráveis instrumentos de gestão de cidades e de prefeituras. Além das pressões dos cidadãos, tal inexorabilidade também está pautada na obediência às legislações mencionadas na Fundamentação Teórica. Essas questões sugerem diferenciadas formas de gerir as cidades e demandam competências austeras dos gestores das cidades nas suas ações cotidianas que envolvem os cidadãos e os diversos atores sociais relacionados com a cidade. Tais competências podem ser traduzidas em atividades de planejamento e gestão municipal para conduzir a cidade com o efetivo apoio participativo dos cidadãos. Essas atividades podem ser facilitadas pela utilização dos sistemas de informação alicerçados pelos recursos da tecnologia da informação e integrados ou alinhados com os planos e planejamentos municipais. Em especial, nas pequenas cidades pesquisadas, essas di- 
ficuldades são maiores considerando as limitações dos múltiplos recursos disponíveis.

Como o objetivo desse trabalho foi de analisar a integração dos sistemas de informação e dos recursos da tecnologia da informação nos planos e nos planejamentos municipais das cidades pesquisadas, algumas considerações foram elaboradas. As considerações descritas nas análises das 14 cidades pesquisadas estão relacionadas com os construtos do protocolo de pesquisa. Com a questionável necessidade de uma Unidade da Tecnologia da Informação nas prefeituras, com as relações com as empresas prestadoras de serviços de sistemas externos e com os pormenores dos recursos da tecnologia da informação. Esses pormenores dizem respeito às questões técnicas quantitativas e qualitativas de software, hardware, gestão de dados e informação, chamando atenção o alto percentual do uso de software proprietário e a dependência dos prestadores de serviços de sistemas (pacotes externos). Também exigem reflexão à falta de informações ou indicadores gerenciais ou estratégicos para fins de apoio às decisões dos gestores das cidades, à pouca integração dos planos municipais e à falta de alguns planejamentos municipais como instrumentos de gestão operacional e estratégica da cidade. $\mathrm{O}$ agravante é que para 4 prefeituras os sistemas de informação e a tecnologia da informação não contribuem efetivamente com os planos e planejamentos municipais e com a gestão das cidades. Essas considerações retratam o questionável percentual declarado de alinhamento da tecnologia da informação com o Plano Plurianual Municipal. No que tange aos indicadores das cidades apresentados, pode-se inferir que existe uma relação com o baixo alinhamento entre os planos e planejamentos municipais e respectivas faltas de efetivas de contribuições dos sistemas de informação e da tecnologia da informação.

Observa-se que apesar das dificuldades apresentadas pelas cidades pesquisadas, principalmente no que tange ao alinhamento dos planos e planejamentos municipais e a tecnologia da informação, não resta dúvida que os sistemas de informação e os recursos da tecnologia da informação, podem contribuir na gestão das prefeituras e no desenvolvimento local das cidades e suas instituições. Eventualmente com a formalidade da elaboração dos planos e planejamentos municipais e com efetiva participação da sociedade civil organizada e seus cidadãos, as cidades que apresentaram baixos indicadores possam melhorar os mesmos. Mas isso não acontece da noite para o dia, será necessário iniciar uma 
adequada estruturação dos dados da cidade para possibilitar a disponibilização compartilhada das informações e dos conhecimentos da cidade e dos cidadãos. A partir dessa estruturação, deve-se ampliar a capacitação e o acompanhamento dos servidores e gestores das cidades nos sistemas de informação e nos recursos da tecnologia da informação, para que os mesmos acreditem nessas ferramentas auxiliares de planejamento e gestão. À medida que internamente na prefeitura se acredite nessas ferramentas, podem-se iniciar trabalhos similares junto aos cidadãos. Nesse sentido, além de favorecer a integração ou o alinhamento, as atividades de planejamento e de gestão municipal podem ser compartilhadas com os cidadãos e com os demais interessados na cidade. Por um lado esse compartilhamento pode ajudar ou tornar menos densa a administração local e as atividades dos Prefeitos e Secretários Municipais, pois as atuações desses gestores de cidades seriam descentralizadas e provavelmente mais ágeis e efetivas. Isso corroboraria com o compartilhamento do poder do governo municipal com os cidadãos e demais interessados na cidade. Por outro lado, a efetiva participação nas atividades de planejamento e de gestão municipal, motiva os cidadãos a entender e vivenciar a cidade. Também valoriza a sua vida cívica, permite o envolvimento no crescimento de sua cidade e possibilita o desenvolvimento de ações sociais e políticas de sua cidade. Isso pode diminuir suas angústias e suas pressões sem propósitos junto à administração municipal. Ambas as abordagens podem cooperar nos fatores competitivos entre as cidades e no conseqüente aumento da disposição moral, social, intelectual e política dos seus cidadãos.

Essa pesquisa reitera a necessidade da integração ou alinhamento e a viabilidade das relações e das contribuições da tecnologia da informação nos planos e planejamentos municipais e na gestão de prefeituras descritas a partir do protocolo de pesquisa definido.

No que tange as contribuições desse trabalho, elas estão direcionadas para a academia, para as cidades participantes e para outras cidades brasileiras e de outros países. Para a academia destacam-se as análises quantitativas e qualitativas realizadas para motivar outros estudos teóricos. O estudo narrado também pode facilitar outras pesquisas aplicadas em cidades e em prefeituras para entender e sugerir alternativas para os seus desafios emergentes de planejamento e de gestão que envolve seus cidadãos, servidores, gestores das cidades e demais interessados na cidade e nas cidades circunvizinhas. Para as cidades e prefeituras pes- 
quisadas esse trabalho contribuiu com a descrição das relações e das contribuições da tecnologia da informação nos planos e planejamentos municipais e na gestão de cidades e prefeituras, permitindo um entendimento mais abrangente sobre essas questões. E para outras cidades esse trabalho pode contribuir no estabelecimento de analogias entre cidades. É possível que boas práticas demonstradas por uma determinada cidade possam ser estendidas para outras cidades ou prefeituras interessadas.

As limitações dessa pesquisa estão relacionadas com o acesso às pessoas responsáveis pelas Unidades de Planejamento e de Informática das prefeituras dispostas a participar do estudo. $\mathrm{E}$ com o método escolhido (estudo de caso múltiplo) que não permite a generalização para todas as cidades brasileiras e de outros países.

Finalizando, observa-se que apesar das dificuldades levantadas nas 14 cidades participantes, o que de fato favorece a integração ou o alinhamento e viabiliza as contribuições e as relações da tecnologia da informação nos planos e planejamentos municipais e na gestão das prefeituras, são os fatores humanos. São os servidores públicos municipais que nas suas atividades operacionais, muitas vezes manuscritas, é que conduzem as prefeituras, pelo esforço individual, inovador e empreendedor, demonstrado nas atividades coletivas e participativas nas cidades. Esses fatores integrados podem diminuir a exclusão social na cidade e aumentar participação política dos cidadãos visando a sua qualidade de vida.

\section{Referências}

Andrade, Nilton de Aquino et al. (2005), Planejamento governamental para municipios: plano plurianual, lei de diretrizes orçamentárias e lei orçamentária anual, Atlas, São Paulo, Brasil.

Bernardes, Nilo (1997), Bases geográficas do povoamento do Estado do Rio Grande do Sul, Ijuí, Unijuí, Brasil.

Bio, Sérgio Rodrigues (1993), Sistemas de informação: um enfoque gerencial, Atlas, São Paulo, Brasil.

Boar, Bernard H. (1993), The art of strategic planning for information technology: crafting strategy for the 90s, John Wiley \& Sons, Nueva York, Estados Unidos. 
Cidades-Ministério das Cidades (2004), Plano diretor participativo: guia para elaboração pelos municípios e cidadãos, CONFEA, Brasília, Brasil.

Cidades-Ministério das Cidades (2005), "Programas Urbanos", http://www.cidades.gov.br, 22 fevereiro 2005.

Codemau-Conselho Regional De Desenvolvimento Do Médio Alto Uruguai (2005), Relatório de Atividades gestão abril/ 2003-abril/2005, Frederico Westphalen, Grafimax.

Estatuto da Cidade (2002), Guia para implementação pelos municípios e cidades, Câmara dos deputados, coordenação de publicações, Brasília, Brasil.

FEE (Fundação de Economia e Estatística. Siegfried Emanuel Heuser), "Resumo estatístico do Rio Grande do Sul. Porto Alegre, 2004”, http://www.fee.rs.gov.br/sitefee/pt/content/ resumo/index.php, 5 jan. 2005.

Ferrari, Célson (1986), Curso de planejamento municipal integrado: urbanismo, Atlas, São Paulo, Brasil.

Freitas, Henrique Mello Rodrigues de, João Luiz Becker, Constantin Metaxa Kladis, y Norberto Hoppen, Informação $e$ decisão: sistemas de apoio e seu impacto, Ortiz, Porto Alegre, Brasil.

Frey, Klaus (2000), "Políticas públicas: um debate conceitual e reflexões referentes à prática da análise de políticas públicas no Brasil", Revista do IPEA, 21, Instituto de Pesquisa Econômica Aplicada, Brasília, Brasil, pp. 211-259.

Gil, Antonio Carlos (1999), Métodos e técnicas de pesquisa social, Atlas, São Paulo, Brasil.

Henderson, John C. e N. Venkatraman (1993), Strategic alignment: leveraging information technology for transforming organizations”, IBM Systems Journal, 32 (1), pp. 4-16.

IBGE (Instituto Brasileiro de Geografia e Estatística), Censo Demográfico 2000. Disponível em: <http://www.ibge.gov.br/ 
home/estatistica/populacao/censo2000>. Acesso em: 21 ago. 2007.

“Índice de Desenvolvimento Socioeconômico" (2003), http:// www.fee.tche.br/sitefee/pt/content/estatisticas/ pg_idese.php?ano, 21 jun. 2007.

Kendall, Kenneth. E. e Julie E. Kendall (1992), Systems analysis and design, Prentice-Hall, Nueva Yersey, Estados Unidos.

Kroenke, David M. (1992), Management information systems, McGraw-Hill, São Paulo, Brasil.

Laudon, Kenneth C. e Jane. P. Laudon (1996), Management information systems: a contemporary perspective, MacMillan, Nueva York, Estados Unidos.

Lederer, Albert L. e R. C. Mahaney (1996), Using Case Tools in strategic information system planning", Information Systems Management Journal, Fall, pp. 47-52.

Llona, Marta, Melisa Luyo e Walter Melgar (2003), La planificación estratégica del desarrollo local en Perú: análisis de casos, Escuela para el desarrollo, Lima, Perú.

Lopes, Rodrigo (1998), A cidade intencional: o planejamento estratégico de cidades, Mauad, Rio de Janeiro, Brasil.

Marconi, Marina de Andrade e Eva Maria Lakatos, Técnicas de pesquisa, Atlas, São Paulo, Brasil.

Marini, Caio (1996), Gestão pública: o debate contemporâneo, Fundação Luis Eduardo Magalhães-Flem, Salvador, El Salvador.

Matus, Carlos (1987), "Planejamento, orçamentos e gerência", Revista ABOP. 29 (88), Brasília, Brasil.

Matus, Carlos (1993), Política, planejamento e governo, IPEA, Brasília, Brasil. 
Mintzberg, Henry, Bruce Ahlstrand, e Joseph Lampel (2000), Safári de estratégia: um roteiro pela selva do planejamento estratégico, Bookman, Porto Alegre, Brasil.

Motta, Paulo Roberto (2004), “Gestão Estratégica”, en Sylvia Constant Vergara e Vera Lúcia de Almeida Corrêa, Propostas para uma gestão pública municipal efetiva, Editora FGV, Rio de Janeiro, Brasil.

Nachmias, David e Chava Nachmias (1987), Research methods in the social sciences, St. Martin's Press, Nueva York, Estados Unidos.

Norton, Peter (1996), Introdução à informática, Makron Books, São Paulo, Brasil.

O'Brien, James A. (2001), Sistemas de Informação e as decisões gerenciais na era da internet, Saraiva, São Paulo, Brasil.

Pfeiffer, Peter (2000), Planejamento estratégico municipal: uma nova abordagem. Textos para Discussão, n. 37, ENAP, Brasília, Brasil.

Premkumar, G. Prem E William R. King (1992), "An empirical assessment of information systems planning and the role of information systems in organizations", Journal of Management Information Systems, 9, Fall, p. 99, Armonk, Estados Unidos.

Rezende, Denis Alcides (2004), "Alinhamento da Tecnologia da Informação ao Planejamento Municipal: Análise da Prática de Gestão de uma prefeitura", en Encontro Anual da Anpad, Curitiba, Anais.

Rezende, Denis Alcides e Belmiro Valverde Jobim Castor (2006), Planejamento estratégico municipal: empreendedorismo participativo nas cidades, prefeituras e organizações públicas, Brasport, Rio de Janeiro, Brasil.

Rockart, John F. e Michael S. Scott Morton (1984), "Implications of changes in information technology for corporate strategy", Interfaces, 14 (1), pp. 84-95. 
Roesch, Sylvia Maria Azevedo (1999), Projeto de estágio e de pesquisa em administração: guia para estágios, trabalhos de conclusão, dissertação e estudos de caso, Atlas, São Paulo, Brasil.

Siedenberg, Dieter Rugard, Andréa Zamin Saad e Carine Maria Senger (2005), "Condicionantes históricos e determinantes contemporâneos do desenvolvimento regional no Rio Grande do Sul” en José Raimundo Carvalho, Klaus Hermanns, Políticas Públicas e Desenvolvimento Regional no Brasil, Fundação Konrad Adenauer, Fortaleza, Brasil.

Stair, Ralph M. (1996), Principles of information systems: a managerial approach, Thomson Publishing, USA.

Turban, Efraim, Ephraim R. Mclean e James Wetherbe (1996), Information technology for management: improving quality and productivity, John Wiley and Sons, Nueva York, Estados Unidos.

Vainer, Ari, Josélia Albuquerque e Sol Garson (2005), Manual de elaboração: o passo a passo da elaboração do PPA para municípios, Ministério do Planejamento, Orçamento e Gestão-Banco Nacional de Desenvolvimento Econômico e Social, Brasília, Brasil.

Vergara, Sylvia Constant (2005), Métodos de pesquisa em administração, Atlas, São Paulo, Brasil.

Yin, Robert K. (1994), Case study research, Sage Pub., Londres, Inglaterra.

Recibido: 5 de junio de 2006. Aceptado: 25 de septiembre de 2007.

Denis Alcides Rezende. É pós-doutor em Administração pela Universidade de São Paulo (FEA/USP), doutor em Gestão da Tecnologia da Informação pela Universidade Federal de Santa Catarina (UFSC), mestre em Informática pela Universidade Federal do Paraná (UFPR), com especialização em Magistério Superior (UTP/ PR), graduado em Administração de Empresas (FADEPS/PR) e em 
Processamento de Dados (FACET-UTT/PR), todas instituições brasileiras. Com diversos cursos na área de informática, administração, gestão, comportamento e didática. Atualmente além de consultor, é professor-pesquisador no Mestrado em Gestão Urbana na Pontifícia Universidade Católica do Paraná no Brasil (PUCPR). Sua linha de pesquisa atual é Planejamento Estratégico municipal e Tecnologia da Informação, com Bolsa PDJ (CNPq). Também leciona na FAE Business School. Seus últimos livros publicados são: Planejamento Estratégico Municipal: empreendedorismo participativo nas cidades, prefeituras e organizações públicas, pela Editora Brasport - Rio de Janeiro; Planejamento de informações públicas municipais: guia para planejar sistemas de informação, informática e governo eletrônico nas prefeituras e municípios, pela Editora Atlas, São Paulo; Sistemas de informações organizacionais: guia prático para projetos em cursos de administração, contabilidade e informática, pela Editora Atlas, São Paulo. É autor e co-autor de mais de 100 artigos científicos publicados (revistas e congressos nacionais e internacionais).

José Augusto Guagliardi. É Ph.D pela University of Texas System (USA), administrador e mestre em administração pela Universidade de São Paulo (FEA/Usp-Brasil). Atualmente é professor titular, pesquisador e livre docente no Programa de Pós-Doutorado da FEA/USP. Sua linha de pesquisa atual é Marketing Municipal, Planejamento Estratégico municipal e Tecnologia da Informação. Seus últimos artigos publicados são: Rezende, D. A.; Guagliardi, J. A. Alinhamento, Contribuições e Relações da Tecnologia da Informação com Planos e Planejamentos Municipais: Survey em Prefeituras Brasileiras na RAUSP - Revista de Administração, 2007; Rezende, D. A.; Guagliardi, J. A. Sistemas de informação e de conhecimentos para contribuir na gestão municipal na Revista Produto \& produção - UFRGS, 2005.

Andréa Zamin Saad. É mestre em Desenvolvimento Gestão e Cidadania pela Universidade Regional do Noroeste do Estado do Rio Grande do Sul (Unijuí). Atualmente é Diretora do PMTec/ URI - Pólo de Modernização Tecnológica do Médio Alto Uruguai e Supervisora do Programa Redes de Cooperação. Atua como docente em cursos de pós-graduação. Sua linha de pesquisa atualmente está ligada à gestão pública e ao desenvolvimento regional. Entre suas publicações destacam-se: A Região do Médio Alto Uruguai do Estado do Rio Grande do Sul. In: Fernando Guilher- 
me Tenório (org.). Cidadania e Desenvolvimento. Ijuí: Unijuí, 2007, v.1, p.427-486. Condicionantes Históricos e Determinantes Contemporâneos do Desenvolvimento Regional no Rio Grande do Sul. In: José Raimundo Carvalho; Klaus Hermanns (Org.). Políticas Públicas e Desenvolvimento Regional no Brasil. 1 ed. Fortaleza/CE: Fundação Konrad Adenauer, 2005, v. 1, p. 211238. Políticas Públicas: da imposição à construção de um processo participativo em busca do desenvolvimento econômico e social, o caso do município de Alpestre/RS, Brasil. In: X Congreso Internacional del CLAD: sobre la Reforma del Estado y la Administración Pública, 2005, Santiago/Chile, 2005. 15p. 